\title{
A "Judicialização da Política" e a "Politização do Judiciário" no Brasil: Notas
} para uma abordagem sociológica

\author{
Fabiano Engelmann \\ Bacharel em Direito UFRGS \\ Mestre em Ciência Política UFRGS \\ Doutorando em Ciência Política UFRGS
}

\section{Resumo}

Este artigo tem por objetivo propor um esquema de análise para o fenômeno da "politização" do direito, observado particularmente a partir da década de 90 no Brasil. A abordagem em tela considera que este comporta para sua apreensão, a consideração simultânea de dois conjuntos de variáveis: Um primeiro, capaz de explicitar a diversidade social dos agentes públicos que hoje ocupam posições nas diversas carreiras jurídicas de estado e, um segundo, que considere o aumento das demandas pela efetivação de direitos, amparados em larga medida na Constituição de 1988. A relação entre estas duas dimensōes é considerada como hipótese explicativa para as transformações no papel institucional, principalmente, do Ministério Público e do Poder Judiciário.

Palavras- chave: politização-carreiras jurídicas-Constituição de 1988

\section{Introdução}

A conjuntura político-institucional do Brasil tem como marco de sua redefinição, a Constituição de 1988. A partir desta nova carta política vislumbra-se a restauração das garantias individuais e políticas perdidas ao longo do regime militar. Este novo marco institucional, ao afirmar o Estado de Direito Democrático reforça o papel das instituições relacionadas à atividade jurisdicional. Neste sentido, abre-se um amplo leque de possibilidades de postulação judicial de direitos consagrados na Constituição, assim como nas legislaçōes que lhe sucedem, como o Estatuto da Criança e do Adolescente e o Código de Defesa do Consumidor, por exemplo. 
Para o cenário político, a conseqüência mais imediata desta nova conjuntura institucional é a ampliação do espaço de atuação dos intérpretes e agentes jurídicos alocados em diversas carreiras de estado como magistratura, promotoria, procuradorias, defensorias públicas, etc. As redefinições dos usos do direito, assim como das carreiras jurídicas e os novos posicionamentos dos juristas frente a sociedade envolvem, entretanto, não apenas uma ampliação de espaço institucional, mas concomitantemente, uma diversificação social no recrutamento dos agentes que atuam nestas profissões. Esta diversificação indica uma quebra num padrão de recrutamento que levava ao fechamento do mundo jurídico afirmando, além do concurso público impessoal e padróes meritocráticos para a ascensão às carreiras de estado, um conjunto de garantias para o exercício de atividades de promotoria e jurisdição. institucional

1. A "politização" do direito e a judicialização da política: $O$ novo papel

No âmbito das carreiras jurídicas uma das expressões visíveis da diversificação nas lutas pela definição do direito legítimo, aparece no espaço das tomadas de posição constatada por (Vianna, 1999 e Arantes, 1997) como "politização" do Poder Judiciário nas décadas de oitenta e noventa. Por um lado, há uma "judicialização da política" (Vianna, op. cit.) cujo exemplo são as ações diretas de inconstitucionalidade junto aos tribunais superiores, onde está expressamente em pauta a disputa em torno do sentido da regra constitucional. Este tipo de ação judicial remete para os tribunais superiores, disputas regionais entre representantes dos poderes executivo e legislativo, pautando o que se poderia estabelecer como um problema tradicional da arena política, na esfera da interpretação jurídica.

Esta "transferência" pode implicar também num imbricamento maior entre as esferas políticas e jurídica no sentido do trânsito de quadros e relaçóes estabelecidas entre agentes que se movem entre esferas de poder. A própria organização interna da instituição opóe os concursos públicos para a justiça de primeiro grau às indicações para a composição dos tribunais superiores, tendendo a clivagem entre instâncias judiciais que julgam conflitos inter-individuais ou referentes, predominantemente, ao direito privado, como a justiça de primeiro grau; e os tribunais superiores mais "políticos".

Diferentemente do direito privado, o direito público calcado no direito constitucional é diretamente vinculado às conjunturas políticas onde determinado grupo institui a regra fazendo "desconhecer o arbitrário da negociação que ela descreve ou "fazendo reconhecer como natural a realidade que ela constrói" (Lacroix, 1992). A recorrência à Constituição como fonte das decisóes judiciais amplia o espaço de possíveis dos confrontos doutrinários, tendo em vista que, como indica (Lacroix, op. cit.) ela pode ser entendida como um recurso mobilizável na luta política: 
"A Constituição deve ser entendida menos como um dado definido, presente na linha de um texto, e mais, como uma construção que tem a marca de sua gênese e de seus usos que deve ser pensada não como repertório apriori e limitativo de açōes para os titulares dos papéis institucionais definidos e sim, como um conjunto de usos menos diferentes do uso de outras formas de recursos utilizados espontaneamente na luta política". (Op. cit, p. 18)

Ou seja, nas lutas pela definição do direito, o recurso à "constitucionalização" superpondo o "direito público" ao "direito privado" implica numa maior "abertura" da interpretação da regra jurídica, possibilitando inclusive, sua "politização".

Por outro lado, relacionado a esta "abertura da arena jurídica", há particularmente a partir da década de 90 , uma "judicialização da vida social" com a crescente entrada para o cenário dos meios jurídicos de um conjunto de problemas identificados aos "novos direitos públicos" (direito do consumidor, direitos humanos, direitos ambientais, direitos sociais e outros). Em termos gerais, esta "judicialização" também caracteriza o aumento do potencial de mediação de conflitos do Judiciário.

A maior legitimação do Judiciário e das instituições ligadas ao meio jurídico pode ser confrontada a um efeito de "descrença" nos canais tradicionais de mediação dos conflitos sociais. Efeito relacionado ao mesmo tempo à diversificação social do recrutamento e às novas definições institucionais das carreiras jurídicas (envolvendo prerrogativas constitucionais e garantias legais, como vitaliciedade, inamovibilidade, irredutibilidade de salários, etc.), que lhes garantem relativa autonomia em relação a outras esferas de poder como o poder executivo e legislativo. Ou seja, estas garantias representam condições de possibilidade, quanto às disposições dos novos agentes recrutados que vão redefinir os usos sociais destas carreiras projetando-as para além de um espaço jurídico restrito e, frequentemente, em enfrentamentos com os outros poderes de estado.

Especificamente, crescem dentro do espaço jurídico segmentos como os promotores públicos e os procuradores da República que passam a atuar em nome da "moralidade pública legítima". No caso do Ministério Público, o monopólio da atuação "em nome da sociedade" legitimado através de garantias institucionais, traz subjacente uma percepção da sociedade brasileira como "hipossuficiente" "incapaz de defender autonomamente seus direitos", assim como, uma crítica aos canais tradicionais de mediação política, como os partidos políticos e o sistema representativo como um todo, associados às práticas de corrupção e clientelismo. (Arantes, 19991)

\footnotetext{
${ }^{1}$ Segundo (Arantes, op.cit), que realizou entrevistas junto a integrantes do Ministério Publico Federal e estadual no Brasil, é recorrente a idéia entre "a oposição entre instituiçōes político-representativas degeneradas e sociedade civil fraca", nesse sentido os promotores entendem que "é preciso que o Ministério Público traga as grandes questões ao Judiciário, e que este funcione como instância de substituição dos políticos incapazes que estão de atender aos apelos da sociedade, por omissão ou mesmo por má-fé" (op cit, pp 96, 97).
} 
Neste sentido, também as lutas dos procuradores e promotores para afirmarem sua "independência", seu espaço socialmente instituído, em relação aos grupos vinculados ao mundo político e burocrático (agentes do legislativo, e do executivo, lato sensu) e também em relação ao Judiciário. Um dos recursos utilizados é a imprensa, particularmente a mídia, que permite quase instantânea repercussão no mundo da política. $O$ uso deste recurso para falar "em nome da sociedade" para um amplo público que transcende os intérpretes do direito, também contribui para a ampliação do espaço dos promotores, em oposição aos magistrados que, sofrem o constrangimento em maior, ou menor grau, da deontologia tradicional da profissáo. Esta consagra o "dever de reserva" e o distanciamento dos juízes em relação aos temas conjunturais da política.

2. O recrutamento para as carreiras jurídicas de estado e as bases sociais para a "politização do direito"

Os estudos que procuram analisar o conjunto destes fenômenos, compreendidos genericamente como "politização do direito", enfocam principalmente o imbricamento entre a política e o direito como um novo papel institucional exercido pelo Poder Judiciário ou pelo Ministério Público que "se politizam." Essas análises², reforçam o perfil das ações judiciais e dos novos direitos passíveis de serem postulados a partir da redemocratização do país com o advento da Constituição de 1988 (Arantes, 1997 e Vianna, op. cit., Silva, 2001 e Cavalcanti, 1999) como um fator determinante neste novo cenário. Nesse sentido, esta "politização" seria absorvida numa "constitucionalização" do direito, fenômeno natural de um processo de "abertura política".

Embora tragam indicações sobre a diversificação social no recrutamento das carreiras jurídicas, tais pesquisas não aprofundam a relação das alteraçōes neste recrutamento e os possíveis tensionamentos e redefinições nas hierarquias de agentes e direitos legítimos advindos com a ampliação da concorrência no interior do espaço jurídico e os diferentes usos ("políticos", "ideológicos" ou "sociais" do direito), daí decorrentes. Os tensionamentos e realinhamentos dos agentes do mundo jurídico coincidem com alterações no recrutamento para as carreiras de estado.

Para o segmento dos magistrados, as mudanças nas origens sociais, são indicadas no trabalho de (Vianna $\left.{ }^{3}, 1997\right)$. Uma amostra de magistrados brasileiros recrutados entre 1974 e 1985 aponta $54 \%$ dos juízes com pais de escolaridade "até o primeiro grau" e 34\% com "perfil ocupacional subalterno". Também demonstra que $72 \%$ dos pais de juízes são funcionários públicos ou empregados de empresas estatais. A mudança na

\footnotetext{
${ }^{2}$ Especificamente sobre o Ministério Público ver (Silva, 2001) e (Cavalcanti,1999)

${ }^{3}$ Ver pesquisas realizadas por ( Bonelli, 1998) e o conjunto de trabalhos do IDESP(Instituto de Estudos Econômicos Socais e Políticos de São Paulo de (Sadek, 1995, 1995b, 1995c, 1998 e 1999)
} 
composição social dos magistrados, exemplificada aqui nas origens familiares, pode ser constatada na comparação com estudos sobre bacharéis incidindo sobre a população do final do século XIX e primeiras décadas do século XX $X^{4}$. No caso do Ministério Público, também as pesquisas realizadas por (Sadek, 1997) em amostra do conjunto dos promotores públicos brasileiros indicam que a maioria dos integrantes apresenta, comparativamente a situação de seus pais, maior renda e escolaridade. $O$ mesmo se aplicando para os integrantes do Ministério Público Federal (Castilho \& Sadek, 1998).

O problema está na relação desta diversificação social com as disposiçōes, por parte desses "novos agentes", ativadas em diversos usos do direito e das carreiras jurídicas. As variáveis a serem consideradas não envolvem apenas as origens sociais dos novos recrutados, mas a relação de suas características sociais com a formação de disposiçōes que desenvolvem. O que implica incluir na análise condicionantes como a formação religiosa e filosófica, por exemplo, obtidas em determinados estabelecimentos escolares ou junto ao grupo familiar, e a relação desta formação com tomadas de posição e determinados usos do direito.

Num nível mais geral, para o problema em pauta relacionado ao espaço de interação de um grupo social cuja legitimidade está calcada na gestão do título de bacharel em direito, na definição das carreiras e do direito frente a diversas esferas sociais, principalmente a esfera política; se destacam uma série de trabalhos que podem servir de referência para a construção de um esquema de análise. Dentre os principais estão os trabalhos de (Cam, 1978), (Bourdieu, 1986), (Bancaud, 1986), (Boigeol, 1986), (Karady, 1991) e os trabalhos de (Yvez Dezalay, 1989, 1992, 1994, 1997, 2001). No conjunto destes trabalhos há a preocupação com o recrutamento para advocacia e as carreiras de estado (particularmente para a magistratura), e as transformações na sua morfologia (Cam, op. cit, Bancaud, op. cit., Boigeol, op. cit.). As hipóteses principais formuladas envolvem a relação entre o recrutamento dos agentes para as carreiras jurídicas e as redefinições da deontologia da carreira, bem como dos usos e definições legítimas do direito

Sobre a estruturação do espaço jurídico e seus princípios de hierarquização os trabalhos de (Bourdieu, 1986, Dezalay, 1989) fornecem indicações que auxiliam num mapeamento mais amplo do espaço de concorrência jurídico:

"As práticas e os discursos jurídicos são com efeito o produto do funcionamento de um campo cuja lógica específica está duplamente determinada: por um lado, pelas relações de força específicas que lhe conferem a sua estrutura e que orientam as lutas de concorrência, ou mais precisamente, os conflitos de competência que nele têm lugar e, por outro lado, pela lógica interna das obras jurídicas que delimitam em cada momento

${ }^{4}$ Para o início do século, ver (Venâncio Filho, 1982), para as décadas de 20, 30 e 40, ver (Miceli, 1979). 
o espaço dos possíveis e, deste modo, o universo das soluções propriamente jurídicas" (Bourdieu, op. cit., 1986 pp. 3, 4)

Esta abordagem leva a considerar na análise, concomitantemente, os mecanismos de recrutamento para as diversas carreiras socialmente instituídas por ritos, símbolos, e garantias legitimadas na força do estado e as tomadas de posição doutrinárias por parte dos agentes frente ao direito. A apreensão dessas condicionantes envolve o mapeamento dos principais pólos em concorrência que se estruturam em função das hierarquias envolvendo carreiras mais ou menos prestigiadas e a relação da trajetória social dos agentes com os mais diversos usos do direito, das carreiras e da "tradição jurídica".

Para o caso francês, (Cam, 1978) ${ }^{5}$ indica a relação entre diversificação escolar, social e a redefinição dos usos do direito. Ao analisar o recrutamento de juízes na França após 1968, explicita a chegada de uma "terceira idade da magistratura francesa". Neste caso, a feminização da população de magistrados, a juvenilização e a mudança nas origens sociais dos juízes recrutados da década de 70 em diante correspondem ao crescimento na magistratura, de uma redefinição das tecnologias de decisão no sentido da preocupação com o "social" e com a "crítica" ao direito positivo tradicional.

Nestas tomadas de posição estão em jogo concomitantemente na definição do posicionamento frente ao direito, a moral religiosa, experiências políticas, e mais amplamente as predisposições para determinadas definiçóes morais da justiça e do uso da carreira de magistrado. No caso analisado, para os magistrados identificados ao direito do trabalho está em pauta uma relação entre uma certa desclassificação social (pertencimento a uma nova fração de classe), uma certa apropriação do catolicismo, posturas políticas de esquerda e concepções de direito:

"Pode-se sugerir a este respeito muitas hipóteses: Em primeiro lugar, se pode invocar a existência de uma espécie de afinidade eletiva entre esta maneira jurídica de se posicionar sobre os problemas sociais e o habitus de classe das novas frações. $O$ fato é que, no caso particular do campo jurídico, o direito do trabalho tem servido de suporte à nova moral, à fé católica e de esquerda; não é surpreendente. Historicamente a isso se prestava: matéria dominada se prestava ao uso dos dominados, o direito do trabalho que continha em si os esquemas da simbologia cristã. (rico/pobre, forte/fraco), não podia deixar de seduzir uma nova fração de classe marginal e católica, à procura de uma nova ética jurídica (Cam, op. cit., p. 23)

A diversificação social da magistratura no caso francês envolve um enfrentamento da deontologia tradicional do corpo magistral. Como exemplo pode-se tomar a fundação

${ }^{5}$ Ver também sobre as oposições entre as características do "magistrado notável' e do "magistrado republicano" e as "crises" advindas dor recrutamento de juízes na França, ( Charle, 1993 e Mounier, 1993) 
do Sindicato da Magistratura que serviu como esfera de aproximação dos magistrados com o conjunto das "lutas trabalhistas"e do Partido Socialista Francês, contribuindo para a redefinição da carreira da magistratura num sentido "social". Esta aproximação está associada também ao fato de os "novos juízes" recrutados dependerem exclusivamente de seus salários, diferentemente dos "antigos magistrados" que complementavam seus proventos a partir de patrimônios e rendas herdados do grupo familiar (Charle, $1993 \mathrm{e}$ Mounier, 1993)

No caso brasileiro, falta uma análise mais aprofundada das relaçóes entre a entrada dos novos agentes nas carreiras de estado e suas respectivas aspiraçóes, disposiçóes sociais, herdadas ou adquiridas, em sua socialização prévia a estas carreiras. Os tipos de engajamentos no movimento estudantil, as pré-disposições adquiridas do grupo familiar, bem como, a relação deste conjunto de disposições que engendram práticas e são operacionalizadas em sua relação com as condições e contextos práticos de ação.

A apreensão das relações destes bacharéis com outras esferas sociais no curso e na socialização prévia à entrada nas carreiras de estado permite, relacionar suas "propriedades de posição e de disposição", para apreensão de certos padrōes de recrutamento e de modalidades de disposiçóes que conduzemà determinadas adesóes políticas. Neste sentido se permite, no âmbito das confrontaçōes doutrinárias, investigar as afinidades objetivas entre a posição social e a disposição, a propensão para posturas de "vanguarda" no enfrentamento ou "conservação" das regras e tradições do mundo jurídico.

\section{Um exemplo de "politização do direito: A definição "alternativa" do direito}

A problematização do "social" no âmbito das carreiras jurídicas tem uma de suas expressões, nas tomadas de posição que referenciadas na "sociologia jurídica" e na "filosofia do direito" protagonizam o debate em torno do "direito alternativo" ou o "uso alternativo do direito". A origem da expressão "alternativos" no âmbito do Judiciário remonta aos movimentos de magistrados ocorridos na Itália e Espanha na década de setenta. No caso italiano, é atribuída (Andrade, 1998) ao alto número de associações de magistrados que surgem após o período fascista, principalmente no final da década de sessenta. $\mathrm{O}$ recrutamento para a magistratura de juízes mais jovens que não haviam passado pelo período de repressão e autoritarismo estatal do fascismo está relacionado à produção das "problemáticas sociais" no âmbito do direito.

Da mesma forma, segundo (Andrade, op. cit.), no caso italiano, as premissas do movimento estavam calcadas na descoberta da "politicidade do direito" e no comprometimento dos juízes alternativos com a "função social do direito". A "politização", neste caso, ocorre nas decisões judiciais legitimadas em nome de princípios constitucionais. Estes, "mais políticos e abertos, em relação ao direito codificado" (op. cit.). Neste sentido, 
se forma uma oposição legítima no interior da magistratura entre decisões baseadas no "principio da legalidade", típico do direito identificado a uma interpretação mais restrita da lei e as alicerçadas nos "princípios gerais de direito", identificados à visão mais "política" do direito. No segundo caso, a "abertura" permitida pelas regras constitucionais vinculadas as lutas políticas conjunturais gera uma permissividade maior para a incorporação da formação ideológica do juiz no ato de julgar. Conforme Andrade (op. cit, p. 51):

"Em realidade, essa prática extremista foi resultado de uma discussão maior, do próprio papel assumido pelos magistrados, de seu poder emblemático na sociedade civil, da própria função repressiva/ideológica do Poder Judiciário. Os membros da Magistratura Democrática para combater esta situação, colocavam como fator crucial a independência do magistrado dentro do próprio Judiciário. Esse, rigorosamente hierarquizado e burocratizado, permitia a uma 'aristocracia' de magistrados, membros da Corte de Cassação, ou presidentes dos demais tribunais, o exercício de poderes ditatoriais"

No caso brasileiro, a constituição de redes de relações ${ }^{6}$ que permitiram a configuração em primeiro lugar do "grupo dos juízes alternativos" e, em segundo lugar do "movimento do direito alternativo", compreende várias etapas de adesão ao grupo desde os que estão ligados por relações de amizade entabuladas antes da formação do grupo, até as adesões mais periféricas por afinidades intelectuais tão-somente. A adesão formada através da circulação de textos e sentenças compreende afinidades intelectuais, cuja apreensão envolve um conjunto complexo de determinações que se estendem desde as características sociais dos agentes em pauta até as experiências, engajamentos e adesões ocorridas anteriormente a seu ingresso na magistratura. Este conjunto conforma certo grau de homogeneização no grupo permitindo afinidades, a formação e reativação de certas pré-disposições e a adesão à "práticas" de determinados usos do direito.

A articulação destas redes ocorre principalmente nos movimentos associativos? e na produção intelectual compreendendo grande edição de livros e publicação de uma revista especializada. O instituto que serve como pólo aglutinador no caso brasileiro é o

\footnotetext{
${ }^{6}$ Sobre a constituição do grupo e do movimento de direito alternativo no Brasil ver (Arruda jr, 1992), (Ferreira e Silva, 1995), (Carvalho, 1998) e (Biavaschi, 1998 )

${ }^{7}$ No manifesto de fundação do Instituto de Direito Alternativo lê-se: "O IDA não é tão somente uma instituição entre outras existentes no pais de crítica ao direito vigente. Outros movimentos importantes surgiram desde a década de setenta, como "O Direito Achado na Rua", sob coordenação do professor José Geraldo Sousa Júnior, O "Ministério Democrático", Os "Juizes para a Democracia, Os Juizes Altemativos", O “Instituto de apoio Jurídico Popular, 0 Grupo de Apoio Jurídico Popular", entre tantos outros coletivos que procuravam dar consecução as teorias nascidas principalmente no contexto da crítica aos desmandos jurídico-político social do regime militar". Roberto Lyra Filho, Luiz Alberto Warat, Luiz Fernando Coelho, José Eduardo Faria, Miguel Pressburger, Roberto Aguiar, entre tantos outros procuravam criar problematizações teóricopolíticas sobre o papel do direito e dos operadores jurídicos nos processos de mudança social." A especificidade do IDA é política e teórica: seu objetivo tem sido o de buscar alinhavar/aproximar atores e instituiçōes de caráter progressistas no Direito, provocando uma maior interlocução entre várias entidades, autores, escolas, que podem sem considerados como críticos em relação do sistema político vigente."(Fonte, site do Instituto)
} 
IDA- Instituto de Direito Alternativo que funciona integrado ao Centro de Ciências Jurídicas e Sociais da Universidade Federal de Santa Catarina-UFSC. Este instituto representa a articulação entre os magistrados e professores do curso de Pós-Graduação em Direito da UFSC, o que possibilitou uma dupla legitimação do movimento, ao mesmo tempo na açắo dos juízes (através de sentenças judiciais e entrevistas à imprensa), e na produção intelectual, haja vista que uma série de teses de doutorado e dissertações de mestrado foram produzidas dentro dos pressupostos das "concepções alternativas" de direito.

A produção intelectual dos juristas identificados com os movimentos alternativos tem por objetivo a reelaboração das disciplinas do "direito tradicional". O investimento por parte deste segmento no debate intelectual reforça a hipótese de que um de seus principais recursos para a ascensão no mundo jurídico se constitui com investimentos no ensino universitário, congressos e seminários de debates intelectuais.

Um indicativo do investimento nas lutas intelectuais é representado pela abundante quantidade de publicaçōes articuladas. O quadro a seguir mostra o intervalo de quatro anos (1991-1995) período considerado de início e auge do movimento, a grande quantidade de livros publicados, praticamente todos pela Editora Acadêmica no qual o grupo possuía influência. Segundo (Andrade, op. cit.), somente após 1993 é que outras editoras específicas começaram a editar "textos alternativos":

Quadro com os livros identificados com a "visão alternativa do direito" publicados entre 1991 e 1995

\begin{tabular}{|c|c|c|c|}
\hline LIVROS & TIRAGEM & DATA & ESGOTADO \\
\hline Juiz alternativo e poder Judiciário & 2.000 & Setembro,1991 & Outubro,1991 \\
\hline Lições de Direito Alternativo, 1 & 2.000 & Setembro, 1991 & Outubro,1991 \\
\hline Lições de Direito Alternativo, 2 & 1.600 & Setembro, 1992 & Outubro, 1994 \\
\hline Magistratura e Direito Alternativo & 3.000 & Maio,1992 & Outubro, 1994 \\
\hline Ministério Público e Direito Alternativo & 3.100 & Maio,1992 & \\
\hline Introdução à Sociologia Jurídica Alternativa & 2.000 & Março,1993 & \\
\hline Direito Alternativo na Jurisprudência & 3.000 & Setembro,1993 & \\
\hline Lições de Direito Alternativo do Trabalho & 1.700 & Novembro, 1993 & \\
\hline Ensino Jurídico e Direito Alternativo & 1.950 & Novembro, 1993 & \\
\hline Razão e Racionalidade Jurídica & 2.100 & Abril,1994 & \\
\hline Revista de Direito Alternativo, 3 & 2.000 & Outubro, 1995 & \\
\hline Liçōes de Direito Alternativo Civil & 2.000 & Maio,1994 & \\
\hline Liçōes Alternativas de Direito Processual & 1.000 & Novembro, 1995 & \\
\hline
\end{tabular}




\section{Considerações finais}

Na proposta de análise em pauta, o caso do "movimento dos alternativos" pode ser lido como um dos tantos exemplos e processos de "politização do direito", principalmente pela visibilidade assumida. A grande questão a investigar é quais os princípios de estruturação do espaço jurídico que dão condições para que grupos de juristas legitimem concepções e usos do direito que cada vez mais aproximam o direito da política, contra uma tradição jurídica firmada em outras bases deontológicas, práticas e epistemológicas.

As questóes expostas, neste artigo, tiveram como objetivo contribuir para um esquema de análise que associe um fenômeno estrutural, representado pela diversificação social das carreiras jurídicas e um fenômeno conjuntural: A "politização do direito". Esta, entendida como fenômeno que amplia o potencial de mediação de conflitos sociais e políticos pelo Poder Judiciário. Neste sentido, não se pretendeu esgotar o assunto, mas apenas expor algumas hipóteses explicativas, algumas já testadas no contexto francês, sobre os princípios que agem na legitimação de grupos, e usos do direito numa sociedade crescentemente diversificada. 


\section{Bibliografia}

ADORNO, S. "Os aprendizes do poder". Rio de Janeiro: Paz e Terra, 1988

ANDRADE, L. R. de. "Introdução ao Direito Alternativo Brasileiro". Porto Alegre: Livraria do Advogado, 1996.

ARANTES, R. B. “Judiciário e Política”. São Paulo, IDESP. Ed. Sumaré, 1997.

ARANTES, R. B. "Direito e Política: O Ministério Público e a defesa dos direitos coletivos. IN: RBCS, vol. 14, n. 39, fevereiro, 1999

ARRUDA jr, Edmundo L (org.). "Liçōes de Direito Alternativo vol. 2". São Paulo, ed. Acadêmica, 1992.

BANCAUD, A \& DEZALAY, Y. "La sociologie juridique comme enjeu social et professionnel”. In Revue Interdisciplinaire des Etudes Juridiques, n. 12, 1984.

BIAVASCHI, M. B. "Magistratura e transformação social: as teses coletivas dos juízes gaúchos”. (dissertação de mestrado) PPGD-UFSC. Florianópolis, 1998

BOURDIEU, P. "La force du Droit: Eléments pour une sociologie du champ juridique” In: Actes dula Recheche en Sciences Sociales. n. 64, sept. 1986.

BOURDIEU, P. Habitus, code et codification In: Actes du la recheche en Sciences Sociales. n. 64, sept. 1986b.

CAM, P."Juges rouges et droit du travail"In: Actes de la Rechercheen Sciences Sociales n. 19, jan, 1978.

CARVALHO, A B. “Teoria e Prática do Direito Alternativo:”. Porto Alegre: Síntese, 1998.

CASTILHO, E. V. \&SADEK, M. T. "O Ministério Público Federal ea Administração da Justiça no Brasil”. São Paulo, IDESP: Sumaré, 1998.

CAVALCANTI, R. B. "Cidadania e Acesso a Justiça: promotores de justiça da comunidade”. São Paulo: IDESP, 1999.

CHARLE, C. "Etat et Magistrat": Les origines d'une crise prolongée". In Actes dela Recherche en Sciences Sociales, n. 96-97, mars. 1993 p. 39-48. 
DEZALAY, Y. SARAT, A., e SILBEY, S. “D'une démarche contestataire à un savoir méritocratique Esquisse d'une histoire sociale de la sociologie juidique américaine.” In: Actes du la Recherche en Sciences Socialesn. 78, juin 1989.

DEZALAY, Y. \& GARTH, B. "The internationalization of Palace of Wars: lawyers, economists, and the contest to transform Latin American State" (The Chicago Series in Law and Society), April, 2001

FERREIRA E SILVA, R. D. "Poder Judiciário e Hegemonia: O caso dos magistrados alternativos no Rio Grande do Sul. (dissertação de mestrado) PPGD-UFSC, Florianópolis, 1995 Juris, 1993.

JUNQUEIRA, Eliane. B. "A sociologia do direito no Brasil” Rio de Janeiro, Lumen

LACROIX, B. "Le politiste et l'analyse des insitutions: Comment parler de la Présidence de la République. In: LACROIX, B. \& LAGROYE, J. Le President de la Repúblique: Usages etgenèses d'une instituion. Paris, Presses de la Fondaion Nationale des Sciences Politiques, 1992. 1979.

MICELI, S. “Intelectuais e Classe dirigente no Brasil (1920-1945). São Paulo, Difel,

MOUNIER, J..P. "Du corps judiciaire à la crise de la magistrature": Les origines d'une crise prolongée". In Actes de la Recherche en Sciences Sociales, nr. 96-97, mars. 1993 p. $39-48$. Idesp, 1995

SADEK, M. T. “O Ministério Público e a Justiça no Brasil”. São Paulo: Sumaré:

SADEK, M. T. "Uma introdução ao estudo da justiça"-São Paulo: DESP: Sumaré, $1995 b$

SADEK, M. T. “O Judiciário em Debate”-São Paulo: IDESP: Sumaré, 1995c

SADEK, M. T. \& CASTILHO, E. W. V. "O Ministério Público Federal e a Administração da Justiça no Brasil "-São Paulo: IDESP: Sumaré, 1998

SADEK, M. T. “O Sistema de Justiça” - São Paulo: IDESP: Sumaré, 1999

SILVA, C. A "Justiça em Jogo: Novas Facetas da atuação dos Promotores de Justiça". São Paulo: Ed. Universidade de São Paulo, 2001 
A "Judicialização da Política" e a "Politização do Judiciário" no Brasil 205

VENÂNCIO FILHO, Alberto. "Das arcadas ao bacharelismo: 150 anos de ensino jurídico no Brasil, -São Paulo: Perspectiva, 1982.

VIANNA, Luiz Werneck Vianna et all. "Corpo e Alma da Magistratura Brasileira”. -Rio de Janeiro: Revan, 1997. $2^{3} \mathrm{ed}$.

VIANNA, Luiz Werneck Vianna et all "A judicialização da política das relações sociais no Brasil", Rio de Janeiro, Revan: setembro de 1999. 